\title{
Registro de Pachymerus nucleorum (Fabricius) (Coleoptera, Chrysomelidae, Bruchinae) Predando Sementes de Licuri em Caetés, Pernambuco, Brasil
}

1. Centro de Tecnologias Estratégica do Nordeste, e-mail: marcelo@cetene.gov.br (Autor para correspondência ${ }^{\bowtie}$ ), izabelle dourado@hotmail.com. 2. Universidade Federal Rural de Pernambuco, e-mail: betobelo@gmail.com. 3. Universidade Federal do Pará, e-mail: coccinellid@gmail.com.

\section{EntomoBrasilis 6 (3): 239-241 (2013)}

Resumo. O objetivo deste trabalho foi registrar a predação de sementes de Syagrus coronata (Martius) (Arecaceae) por larvas de Pachymerus nucleorum (Fabricius), no município de Caetés, Pernambuco nordeste do Brasil. Os frutos foram coletadas de 10 plantas adultas de Syagrus coronata (Arecaceae) no entorno da usina experimental de biodiesel de Caetés-PE, após a definição de um raio de 1,5 m ao redor da copa, esta foi dividida em quatro quadrantes, e através de sorteio, foi colocado um coletor no quadrante vencedor a 1m da estipe. Na análise os frutos com orifício de saída e/ou pela presença da larva no processo de liberação da amêndoa, o nível de infestação alcançou 80\% dos frutos analisados. Em outra situação amêndoas aparentemente sadias, ou seja, sem danos superficiais foram observadas diariamente por 60 dias as quais, ocorreram $18 \%$ de emergência de larvas até os 41dias, atingindo o pico da predação entre o décimo e o décimo oitavo dia, com $48 \%$ de toda predação.

Palavras-chave: Bicho coco; Palmeira; Predação; Syagrus coronata.

\section{Record of Pachymerus nucleorum (Fabricius) (Coleoptera, Chrysomelidae, Bruchinae) Preying Seeds of Licuri in Caetés, Pernambuco, Brazil}

\begin{abstract}
The aim of the present study was to observe seed predation by larvae of Pachymerus nucleorum (Fabricius) on seeds of Syagrus coronata (Martius) (Arecaceae) in Caetés, Pernambuco, northeastern Brazil. Fruits of 10 adult plants of $S$. coronata were collected in the surroundings of the experimental biodiesel plant of Caetés. The projection of the crown within $1.5 \mathrm{~m}$ from the stipe was devided into four quadrants, one of which was randomly selected for sampling. In the first analysis of the larvae presence or their holes of emergence, the infestation level reached $80 \%$ of the analyzed fruits. In an another situation, apparently uninfested fruits (without superficial damage) were daily observed for 60 days, occurring $18 \%$ of larvae emergence within 41 days, with the peak of predation between the tenth and the eighteenth day, period in which $48 \%$ of total predation was observed.
\end{abstract}

Keywords: Coconut bug; Palm; Predation; Syagrus coronata.

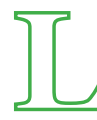

icuri (Syagrus coronata) (Martius) Beccari, pertence à família Arecaceae (Noblick 1991). Palmeira típica do semiárido nordestino, a espécie tem uma boa adaptação às regiões secas da caatinga, abrangendo o norte de Minas Gerais, ocupando toda a porção oriental e central da Bahia, até o sul de Pernambuco, incluindo também os Estados de Sergipe e Alagoas (Noblick 1991), sendo conhecida ainda por aricuri, nicuri, alicuri e ouricuri.

A frutificação de $S$. coronata começa seis anos após o plantio. A produção média anual em um hectare nativo de licuri é de 2.00o Kg de frutos. Nos anos de pluviosidade abaixo da média, a produção diminui, porém sempre ocorre de maneira satisfatória. No entanto, em um licurizal bem plantado e bem cultivado, a produção não deverá ser inferior a 4.000 Kg.ha-1 ${ }^{-1}$ SANTOS \& SANTOS 2002 citado por DRUMOND 2007).

A propagação de $S$. coronata é feita exclusivamente de forma sexuada. Como a maioria das espécies de palmeiras, o licuri apresenta dificuldades para germinar, mesmo sob condições adequadas (CUNHA \& JARDIM 1995).

Além de (RuFino et al. 2008) que aplicaram um questionário em comunidades da Bahia e descobriram 32 utilizações do licuri, destacando-se o óleo, leite de coco, farinha, cocada e aplicações em artesanato, o (CEFET-BA 2006), através do projeto interdisciplinar licuri, iniciou uma pesquisa sobre o uso alimentício do produto como enriquecimento da merenda escolar. Ainda, espera-se a promoção do trabalhador rural, melhoria da qualidade de vida no campo, conscientização sobre o planejamento rural e incentivo ao agronegócio do biodiesel. O licuri vem desta forma despertando grande interesse por parte dos produtores rurais do sertão nordestino em manejar seus povoamentos naturais e até mesmo em estabelecer novos plantios para fins de produção de biodiesel (DRUMOND 2007).

A predação de sementes pode limitar o recrutamento de plantas, reduzindo o número de sementes viáveis disponíveis (JANZEN 1971). Segundo (JoHnson et al. 1995), são frequentes as citações da relação da predação de frutos de palmeiras com besouros da subfamília Bruchinae. Segundo os mesmos autores, para a larva do bruquíneo, a semente representa um alimento rico e bem protegido do ambiente e de predadores, enquanto que os adultos se alimentam apenas de pólen e néctar.

Pachymerus nucleorum (Fabricius), é conhecido popularmente como bicho-do-coco e suas larvas são consumidas por algumas populações humanas, que coletam os cocos e consomem os insetos crus ou fritos (Costa-Neto 2004). Entre as palmeiras que

Agência de Financiamento: FINEP 
T $P$. nucleorum utiliza, encontram-se espécies economicamente importantes tais como carnaúba (Copernicia cerifera Mart.), coco da Bahia (Cocos nucifera L.) e babaçu (Orbignya phalerata Mart) (GARCIA et al. 1980).

Assim, o objetivo deste trabalho foi registrar a predação de sementes de $S$. coronata por larvas de $P$. nucleorum, no município de Caetés, Pernambuco.

Foram coletados frutos de $S$. coronata, na área experimental de oleaginosas do Centro de Tecnologias Estratégicas do Nordeste (CETENE) entre os meses de fevereiro e abril de 2011, estes foram avaliados no laboratório da usina experimental de biodiesel do CETENE, localizada no município de Caetés (o8 $47^{\circ}$ '0,7”'S; $36^{\circ} 36^{\prime} 47,3$ 'W). Os frutos foram coletados de 10 plantas adultas no entorno da usina experimental de biodiesel de Caetés-PE, após a definição de um raio de 1,5m ao redor da copa, esta foi dividida em quatro quadrantes, e através de sorteio, foi colocado um recipiente coletor no quadrante vencedor a $1 \mathrm{~m}$ da estipe. Após 45 dias, todos os frutos contidos nos 10 coletores foram coletados, misturados em um recipiente de $10 \mathrm{~L}$ e levados ao laboratório para selecionar os frutos maduros (coloração amarela) para as avaliações. Selecionaram-se cem frutos ao acaso, despolpados, submetidos à liberação das amêndoas, e estes foram avaliados como predado ou não pela presença da larva de $P$. nucleorum. Em outra situação, cem amêndoas oriundas da amostra selecionada de frutos maduros de $S$. coronata, isentas de sintomas externos de predação por larvas de $P$. nucleorum, foram distribuídas em uma bandeja plástica telada de 5 x $40 \mathrm{x}$ $30 \mathrm{~cm}$ e observadas diariamente para verificar a ocorrência de predação das amêndoas, identificada pela presença das larvas.

$\mathrm{Na}$ análise dos frutos com orifício de saída e/ou pela presença da larva no processo de liberação da amêndoa, o nível de infestação alcançou 80\% dos frutos analisados. Resultado muito semelhante ao encontrado por (GARCIA et al. 1980) que estudando a predação de frutos da espécie $S$. oleracea, por $P$. nucleorum em vários municípios de Goiás, encontrou uma variação na predação entre 42,03\% e 84,5\%. (GRENHA et al. 2008), trabalhando com Allagoptera arenaria (Gomes) (Arecaceae), registrou taxas de predação de $P$. nucleorum que variou de 14 a $46 \%$ nas áreas coletadas. Os altos percentuais de infestação podem ser explicados pela dificuldade na ação de inimigos naturais, devido o comportamento e ecologia do inseto. Em outra situação amêndoas aparentemente sadias e sem danos superficiais foram observadas diariamente por 60 dias, das quais, ocorreu $18 \%$ de emergência de larvas até os 41 dias, em intervalos que variaram entre três e 12 dias atingindo o pico da predação entre o décimo e o décimo oitavo dia, com $48 \%$ de toda predação. Os danos no endocarpo não são suficientes para identificar o nível de infestação, como confirmado por (Link \& NAIBO 1995), que afirmam que somente o exame superficial do fruto, subestima o nível de infestação, havendo necessidade de quebra dos caroços para a comprovação do ataque efetivo. Neste estudo foram identificados todos os estágios de desenvolvimento de P. nucleorum (Figura 1).
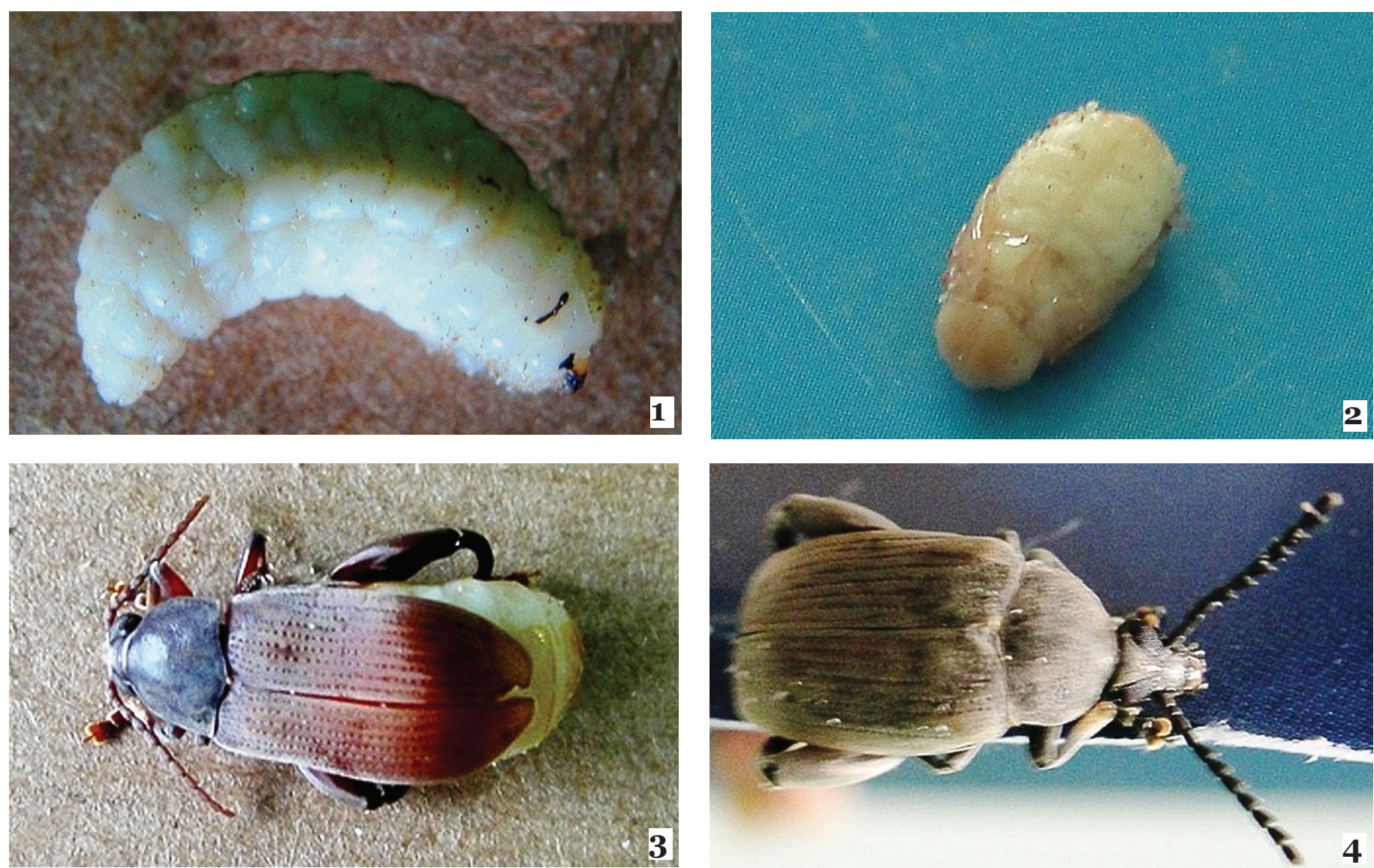

Figura 1. Fases de desenvolvimento P. nucleorum (Larva (1), Pupa (2), Adulto jovem (3) e Adulto (4)). (Foto: Andrade, M.B.).

\section{AGRADECIMENTOS}

Ao Centro de Tecnologias Estratégicas do Nordeste (CETENE), pelo apoio aos estudos desenvolvidos e ao Programa de Pósgraduação em Entomologia Agrícola da Universidade Federal Rural de Pernambuco, pela colaboração.

\section{REFERÊNCIAS}

CEFET-BA, 2006. Licuri como fonte energética in: Licuri, Ministério da Educação, cartilhas temáticas. 26p. Disponível em: <http://portal.mec.gov.br/setec/arquivos/pdf/cartilha licuri.pdf. $>$ [01/ 12/2011].

Costa-Neto, E.M., 2004. Insetos como recursos alimentares nativos no semiárido do estado da Bahia, nordeste do Brasil. Zonas Áridas, 8: 33-40. 
Cunha, A.C.C. \& M.A.G. Jardim, 1995. Avaliação do potencial germinativo em açaí (Euterpe oleracea Mart.) variedades preto, branco e espada. Boletim do Museu Paraense Emílio Goeldi, 11: 55-60.

Drumond, M.A., 2007. Licuri Syagrus coronata (Mart.) Becc. Petrolina: Embrapa Semiárido, 2007.16p. (Embrapa Semiárido. Documento on line, 1999). Disponível em: <http:// www.cpatsa.embrapa.br/public eletronica/downloads/ SDC199.pdf $>$ [01/12/2011].

Garcia, A.H., J.A.M. Rosa \& M.G.G. Costa, 1980. Contribuição ao conhecimento do ataque de Pachymerus nucleorum Fabr., 1792 (Bruchidae: Coleoptera) em Syagrus oleraceae Mart. (Palmae). Anais da Escola de Agronomia e Veterinária, 10: 5-11.

Grenha, V., M.V. Macedo \& R.F. Monteiro, 2008. Predação de sementes de Allagoptera arenaria (Gomes) O' Kuntze (Arecaceae) por Pachymerus nucleorum Fabricius. (Coleoptera, Chrysomelidae, Bruchinae). Revista Brasileira de Entomologia, 52: 50-56.
Janzen, D.H., 1971. Seed predation by animals. Annual Review of Ecology and Systematics. 2: 465-492.

Johnson, C.D., S. Zona \& J.A. Nilsson, 1995. Bruchid beetles and palms seeds: recorded relationships. Principes, 39: 25 -35.

Link, D. \& J.G. Naibo, 1995. Nível de Infestação de Butiobruchus sp em amêndoas de Butiazeiro. Ciência Rural, 24: 201-203.

Noblick, L.R., 1991. The indigenous palms of the State of Bahia Brazil. (PhD) Thesis-University of Illinois, Chicago. 523 p.

Rufino, M.U.L., J.T.M. Costa, V.A. Silva \& L. H. C. Andrade, 2008. Conhecimento e uso do ouricuri (Syagrus coronata) e do babaçu (Orbignya phalerata) em Buíque, PE, Brasil. Acta Botânica Brasílica, 22: 1141-1149.

\section{Recebido em: 25/o7/2012}

Aceito em: 09/o7/2013

\section{Como citar este artigo:}

Andrade, M.B., A.B. Esteves Filho, I.T.D. Siqueira \& J.A. Giorgi, 2013. Registro de Pachymerus nucleorum (Fabricius) (Coleoptera, Chrysomelidae, Bruchinae) predando sementes de Licuri em Caetés, Pernambuco, Brasil. EntomoBrasilis, 6(3): 239-241.

Acessível em: http://www.periodico.ebras.bio.br/ojs/index.php/ebras/article/view/262. doi:10.12741/ebrasilis.v6i3.262
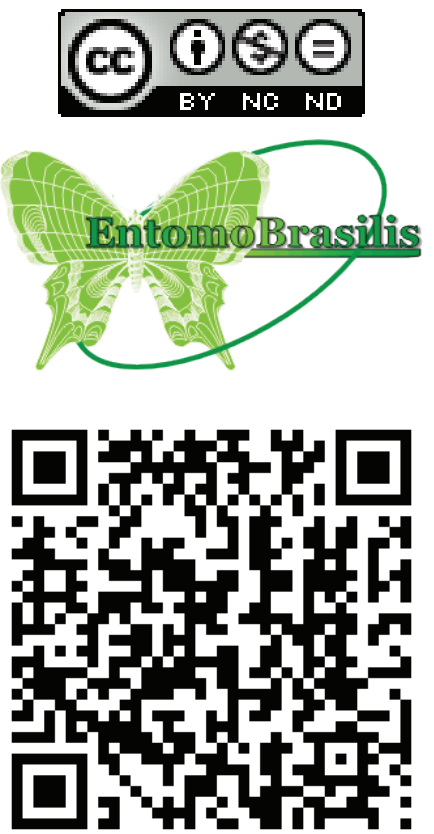